\title{
Obesity- and age-related alterations in FAT/CD36 translocation and lipin-1 subcellular localization in skeletal muscle of the Zucker rats
}

\author{
Snjezana Romic ${ }^{1}$, Katarina Krskova ${ }^{2}$, Rafal Olszanecki³ ${ }^{3}$ Lucia Balazova ${ }^{2}$, Viktoria Lory ${ }^{2}$, \\ Goran Koricanac ${ }^{1}$, Miroslava Slamkova ${ }^{2}$ and Stefan Zorad ${ }^{2}$ \\ ${ }^{1}$ Laboratory for Molecular Biology and Endocrinology, Vinca Institute of Nuclear Sciences, University of Belgrade, Belgrade, \\ Serbia \\ ${ }^{2}$ Institute of Experimental Endocrinology, BMC, SAS, Bratislava, Slovakia \\ ${ }^{3}$ Chair of Pharmacology, Jagiellonian University Medical College, Cracow, Poland
}

\begin{abstract}
Fatty acid (FA) uptake and/or intramuscular triglyceride (TG) accumulation in skeletal muscle are increased in obesity, type 2 diabetes and aging. FA translocase (FAT/CD36) translocation, lipin-1 subcellular localization and nuclear factor kappa $B(N F-\kappa B)$ p 65 protein content in quadriceps muscle of young and old obese Zucker $f a / f a$ rats and their lean controls were analyzed by immunoblot to define obesity- and aging-related alterations in FA uptake, their subsequent metabolic fate and potential to activate pro-inflammatory signaling. As expected, obesity increased FAT/CD36 content in plasma membrane in quadriceps muscle of $f a / f a$ rats. Aging increased cytosolic lipin- 1 content in both, obese rats and their lean controls. Also, old obese rats had decreased level of nuclear extract lipin-1 compared to that in old lean rats. Neither obesity nor age altered NF- $\kappa B$ p 65 protein content in cytosol and nuclear extract of quadriceps muscle suggesting that obesity/aging-induced changes in FA handling are not accompanied by NF- $\mathrm{kB}$-mediated inflammation. Increase in plasma membrane FAT/CD36 content in obese rats and failure in lipin-1 export to nucleus with progression of obesity, implying an increase in FA uptake and their different channeling into lipid intermediates synthesis pathway in old $f a / f a$ rats versus FA usage in lean rats of the same age.
\end{abstract}

Key words: Obesity — Aging — Skeletal muscle — FAT/CD36 — Lipin-1

\section{Introduction}

Fatty acids (FA) are an important source of energy for many tissues, including skeletal muscle, which is the main site of the manifestation of insulin resistance (Cahova et al. 2007). Skeletal muscle displays "metabolic inflexibility" of FA utilization in insulin resistance, which is characterized by impaired ability to switch easily from fat oxidation during fasting conditions to glucose oxidation under insulin-stimulated conditions (Kelley and Mandarino 2000; Cahova et al. 2007).

Fatty acid uptake across the plasma membrane is a largely protein-mediated mechanism and it involves several transport proteins, including a family of $\sim 70-\mathrm{kDa} F A$ transport

Correspondence to: Snjezana Romic, Laboratory for Molecular Biology and Endocrinology, Vinca Institute of Nuclear Sciences, University of Belgrade, P.O. Box 522, 11001 Belgrade, Serbia

E-mail: snjezana.romic@vin.bg.ac.rs proteins (FATP1-6), the 40-kDa plasma membrane associated FA binding protein (FABPpm) and the heavily glycosylated $88-\mathrm{kDa}$ FA translocase, also known as CD36 (FAT/ CD36) (Bonen et al. 2003, 2007). Bonen et al. suggest that FAT/CD36 is a key FA transport protein in heart and skeletal muscle (Bonen et al. 2004a). FA uptake is regulated either by altering the expression and/or subcellular localization of the FA transporters, where both contraction and insulin have been shown to induce the translocation of intracellular stored FAT/CD36 to the plasma membrane to increase FA uptake (Koonen et al. 2005).

It was found that rate of FA uptake in skeletal muscle is increased in obese and type 2 diabetic humans (Bonen et al. 2004b) and in obese Zucker rats (Luiken et al. 2001). Obese individuals have increased intramuscular triglyceride (TG) content and it strongly coincides with an upregulation of the long chain FA transport across the sarcolemma (Bonen et al. 2004b; Li et al. 2011). Also, FA uptake under insulin- 
stimulated conditions is increased in muscle of the old rats and rate of FA uptake is correlated with rate of TG synthesis (Tucker and Turcotte 2003). In addition, aging is accompanied by higher muscle protein expression of FAT/CD36 and higher muscle TG levels (Tucker and Turcotte 2003).

Lipin-1 is a member of enzyme family that exhibits phosphatidate phosphatase-1 enzyme activity, which converts phosphatidate to diacylglycerol (DAG) on membranes of the endoplasmic reticulum in TG synthesis pathway. Lipin proteins resides in the cytosol and they also can localize to nucleus, where lipin- 1 can act as transcriptional co-activator (Reue and Brindley 2008; Siniossoglou, 2013). Lipin-1 accounts for all of the phosphatidate phosphatase-1 activity in mouse skeletal muscle (Donkor et al. 2007). Lipid accumulation within muscle cells is associated with skeletal muscle insulin resistance (Machann et al. 2004), where different lipid intermediates such as fatty acyl-CoA, ceramides and DAG, inhibit specific steps in the insulin signaling cascade (Timmers et al. 2008; Tsatsoulis et al. 2013).

In obesity and associated diseases, chronic inflammation is characterized by elevated expression of pro-inflammatory cytokines and activation of pro-inflammatory signaling pathways primarily in adipose tissue and liver (Ye 2013). However, activation of nuclear factor kappa B (NF- $\kappa \mathrm{B})$ and p38 mitogen-activated protein kinase (MAPK) proinflammatory signaling is also seen in skeletal muscle in obesity and diabetes type 2 (Sishi et al. 2011; Brown et al. 2015). The prototypical NF- $\kappa B$ is a heterodimer of $\mathrm{p} 50$ and p65 subunits and it is responsible for the majority of NF- $\kappa B$ activity in skeletal muscle (Kramer and Goodyear 2007; Huang et al. 2010). Posttranslational modifications of the p65 subunit play an important role in regulation of transcriptional activity of NF- $\kappa \mathrm{B}$ (Huang et al. 2010). Lipid-induced insulin resistance in human skeletal muscle is associated with DAG accumulation, increased protein kinase $C$ activity and decreased inhibitor of kappa B-alpha (I $\mathrm{B}-\alpha)$ content (Itani et al. 2002) that can lead to NF- $\kappa B$ migration from cytosol to the nucleus, where it promotes the transcription of proinflammatory tumor necrosis factor alpha (TNF- $\alpha$ ) (Baker et al. 2011). Also, higher ceramide content was associated with an increased phosphorylation and protein content of the NF- $\kappa$ B p65 in skeletal muscle of old man (Rivas et al. 2012).

Considering literature data showing that both obesity and aging are accompanied by increased FA uptake and TG accumulation in skeletal muscles, we hypothesized that FAT/ CD36 and lipin-1, molecules involved in these processes, might be affected by obesity and/or old age. We analyzed FAT/CD36 translocation and lipin-1 subcellular localization in quadriceps muscle of 3-months-old (young) and 8-months-old (old) obese Zucker $f a / f a$ rats and their lean controls. Potential activation of pro-inflammatory NF- $\kappa \mathrm{B}$ signaling, through determination of NF- $\mathrm{B}$ p 65 nuclear localization, was also studied.

\section{Materials and Methods}

\section{Chemicals}

Reagents for the bicinchoninic acid (BCA) assay were purchased from Sigma-Aldrich (St. Louis, MO, USA). Reagents for Bradford protein assay and the Coomassie Plus ${ }^{\mathrm{TM}}$ were purchased from Thermo Fisher Scientific (Waltham, MA, USA). Rabbit polyclonal anti-lipin-1 antibody (sc-98450), rabbit polyclonal anti-FAT/CD36 (sc-9154) and rabbit polyclonal anti-NF- $\kappa$ B p65 (sc-372) antibodies were obtained from Santa Cruz Biotechnology, Inc. (Santa Cruz, CA, USA). Mouse monoclonal anti- $\beta$-tubulin (926-42211) antibody was purchased from Li-Cor Biosciences (Lincoln, NE, USA). Anti-rabbit IgG (H+L) (DyLight ${ }^{\text {Tm }} 800$ Conjugate) and Antimouse IgG $(\mathrm{H}+\mathrm{L})\left(\right.$ DyLight $^{\mathrm{Tm}} 800$ Conjugate) were purchased from Cell Signaling Technology (Beverly, MA, USA).

\section{Animals}

Male Zucker fatty rats $(f a / f a)$ and their lean controls (+/?) aged 9 weeks were purchased from Harlan (Udine, Italy). The animals were housed in a 12-hour light/dark cycle with access to water and standard diet ad libitum. Overnightfasted animals were killed at the age of 3 (young) resp. 8 (old) months by decapitation. Experimental procedures involving animals were approved by the Jagiellonian University Ethical Committee on Animal Experiments.

\section{Plasma membrane isolation}

Membrane fraction was prepared by modification of Jarett's method (Jarett 1974). Powderized quadriceps muscles were homogenized with a glass-teflon homogenizer in Tris-EDTA buffer (10 mmol/l Tris-HCl, $250 \mathrm{mmol} / \mathrm{l}$ sucrose, $1 \mathrm{mmol} / \mathrm{l}$ EDTA, $1 \mathrm{mmol} / \mathrm{l}$ phenylmethylsulphonyl fluoride, $5 \mu \mathrm{g} /$ $\mathrm{ml}$ aprotinin, $5 \mu \mathrm{g} / \mathrm{ml}$ leupeptin, $10 \mathrm{mmol} / \mathrm{l} \mathrm{NaF}, 1 \mathrm{mmol} / \mathrm{l}$ $\mathrm{Na}_{3} \mathrm{VO}_{4}, 30 \mathrm{mmol} / \mathrm{l}$ sodium pyrophosphate, $\mathrm{pH}$ 7.4). Homogenates were centrifuged at $1000 \times g$ for $10 \mathrm{~min}$ at $4^{\circ} \mathrm{C}$. After centrifugation of supernatants at $16000 \times g$ for $15 \mathrm{~min}$ at $4^{\circ} \mathrm{C}$, the pellet of crude plasma membranes was obtained and resuspended in Tris-EDTA buffer. The supernatant was denoted as cytosol. Protein concentration was determined by the BCA assay using bovine serum albumin as a standard.

\section{Preparation of nuclear extract}

Nuclear proteins were isolated according to modified method previously described (Helenius et al. 1996). Tissue was homogenized with a glass-teflon homogenizer in ice-cold hypotonic buffer $(1.5 \mathrm{mmol} / \mathrm{l} \mathrm{MgCl} 2,10 \mathrm{mmol} / \mathrm{l} \mathrm{KCl}, 0.5 \mathrm{mmol} / \mathrm{l}$ DTT, $10 \mathrm{mmol} / \mathrm{l}$ HEPES, protease and phosphatase inhibitors, $\mathrm{pH}$ 7.9). Homogenates were incubated for $10 \mathrm{~min}$ on 
ice and centrifuged at $21000 \times g$ for $20 \mathrm{~min}$ at $4^{\circ} \mathrm{C}$ and the supernatant was recentrifuged at $15000 \times g$ for $30 \mathrm{~min}$. The obtained supernatant was designated the cytosol fraction. Nuclear proteins were isolated from the original pellet. Pellets were washed once with the same volume of hypotonic buffer and centrifuged at $10000 \times g$ for $15 \mathrm{~min}$ at $4^{\circ} \mathrm{C}$. Supernatants were discarded and pellets were suspended in ice-cold low salt buffer (25\% glycerol, $1.5 \mathrm{mmol} / 1 \mathrm{MgCl}_{2}, 0.2 \mathrm{mmol} / \mathrm{l}$ EDTA, $0.5 \mathrm{mmol} / 1 \mathrm{DTT}, 20 \mathrm{mmol} / \mathrm{l} \mathrm{KCl}, 20 \mathrm{mmol} / \mathrm{l} \mathrm{HEPES}$, protease and phosphatase inhibitors, $\mathrm{pH}$ 7.9) using the half of the volume of hypotonic buffer. Nuclei were lysed by adding high salt buffer ( $25 \%$ glycerol, $1.5 \mathrm{mmol} / 1 \mathrm{MgCl}_{2}, 0.2 \mathrm{mmol} / \mathrm{l}$ EDTA, $0.5 \mathrm{mmol} / 1 \mathrm{DTT}, 1.2 \mathrm{~mol} / \mathrm{l} \mathrm{KCl}, 20 \mathrm{mmol} / \mathrm{l} \mathrm{HEPES}$, protease and phosphatase inhibitors, $\mathrm{pH}$ 7.9) drop by drop using the half of the volume of low salt buffer. Samples were incubated on ice and frequently mixed for $30 \mathrm{~min}$. The obtained suspension was centrifuged for $40 \mathrm{~min}$ at 21000 $\times g$, and the supernatant was referred to as a nuclear extract. Protein concentration was determined by the BCA assay (cytosol) or Bradford assay (nuclear extract) using bovine serum albumin as a standard.

\section{Western blotting}

Plasma membrane, nuclear extract and appropriate cytosol proteins were separated on $8 \%$ SDS polyacrylamide gels and transferred to a PVDF membrane. Membranes were blocked in 5\% milk in TBS/IGEPAL buffer and incubated overnight at $4^{\circ} \mathrm{C}$ with appropriate primary antibody diluted 1:500 (FAT/CD36, lipin-1 and NF- $\kappa$ B p65) or 1:2000 ( $\beta$-tubulin) in blocking buffer. After washing, membranes were incubated with secondary antibody conjugated to fluorescent dye diluted 1:15000. The bands were visualized and quantified using the LI-COR ${ }^{\circledR}$ Biosciences Odyssey ${ }^{\circledast}$ Infrared Imaging System. The band intensities were normalized using $\beta$-tubulin as an internal loading control for cytosol fractions. Total protein stains with coomassie blue brilliant were used to normalize expression of target protein in the plasma membrane fraction and nuclear extract (Welinder and Ekblad 2011). Briefly, after membrane scanning and subsequent washing, blots were stained for $1 \mathrm{~min}(0.04 \%$ coomassie blue brilliant (w/v), $40 \%$ methanol (v/v) and $5 \%$ acetic acid (v/v)), destained for 2 min (40\% methanol (v/v) and $5 \%$ acetic acid (v/v)), washed in water and dried. Signal corresponding to total proteins on the blot was analyzed by software Image J 1.42q (NIH, USA).

\section{Statistical analysis}

All data are presented as mean \pm SEM. Statistical comparisons were performed by two-way ANOVA with a Bonferroni test for post hoc comparison using Sigma Stat 3.5 (Systat
A

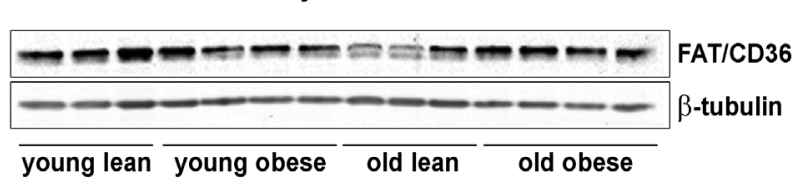

B
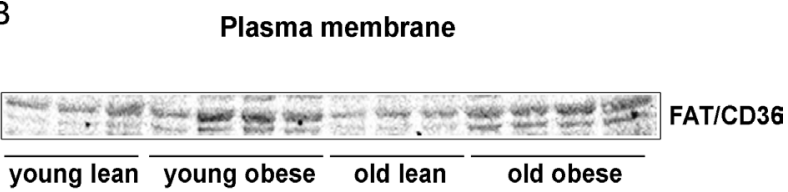
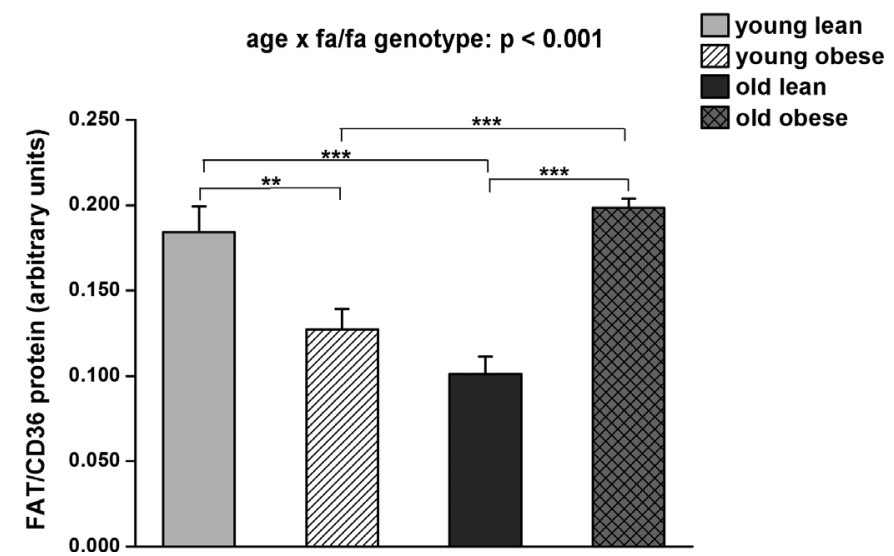

fa/fa genotype: $p=0.005$

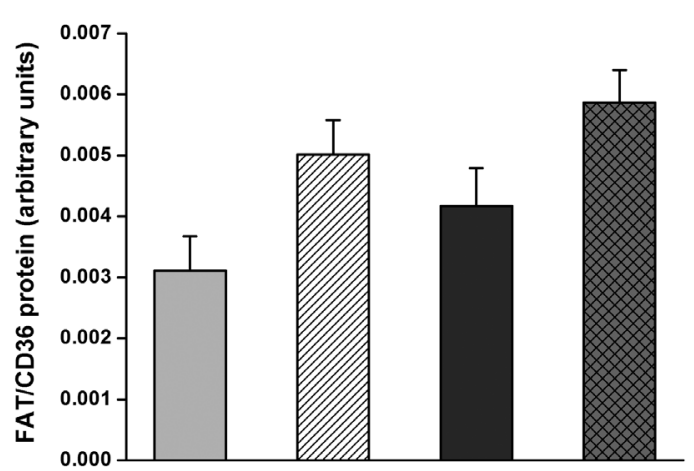

Figure 1. FAT/CD36 protein content in cytosol (A) and plasma membrane (B) in quadriceps muscle of 3- (young) and 8-months-old (old) obese Zucker $f a / f a$ rats and their lean controls (lean). Representative Western blots are shown. Results of densitometric quantification of the Western blots after normalization to appropriate loading control are presented as mean \pm SEM. Statistical analysis was calculated by two-way ANOVA, followed by Bonferroni post hoc test. $n=8$ for young obese, $n=8$ for old obese, $n=6$ for young lean and $n=6$ for old lean for each fraction. ${ }^{* *} p<0.01,{ }^{* * *} p<0.001$. 
Software Inc., San Jose, California, USA). A value of $p<0.05$ was considered statistically significant.

\section{Results}

\section{FAT/CD36 translocation in quadriceps muscle}

To study effects of obesity and aging on FAT/CD36 translocation, plasma membrane and cytosol content were determined. Content of FAT/CD36 in cytosol of quadriceps muscle in obese Zucker rats is dependent on age or progression of obesity associated with age. The two-way ANOVA revealed a significant interaction between age and genotype $\left(\mathrm{F}_{(1,24)}=49.421, p<0.001\right)($ Figure $1 \mathrm{~A})$. Bonferroni post hoc test revealed significantly decreased level of cytosolic FAT/CD36 in young obese rats compared to that in young lean rats $(p=0.001)$, while there was significantly increased FAT/CD36 content in cytosol of old obese rats compared to old lean rats $(p<0.001)$. In addition, significantly increased cytosolic FAT/CD36 was observed in old obese rats compared to that in young obese rats $(p<0.001)$. Contrary, there was significantly decreased level of cytosolic FAT/CD36 in old lean compared to young lean rats $(p<0.001)$.

A

Cytosol

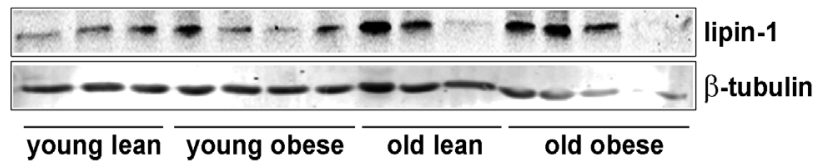

Two-way ANOVA revealed a significant main effect of the $f a / f a$ genotype $\left(\mathrm{F}_{(1,24)}=9.739, p=0.005\right)$ on plasma membrane FAT/CD36 content (Figure 1B). Obesity increased FAT/CD36 content in plasma membrane in quadriceps muscle of $f a / f a$ rats. Neither a significant effect of age $\left(\mathrm{F}_{(1,24)}\right.$ $=2.751, p=0.110)$ nor an interaction between age and genotype $\left(\mathrm{F}_{(1,24)}=0.0337, p=0.856\right)$ were observed.

\section{Lipin-1 subcellular localization in quadriceps muscle}

An effect of obesity and aging on subcellular localization of lipin-1 was studied through determination of lipin-1 protein content in cytosol and nuclear extract. Lipin-1 cytosolic content in quadriceps muscle of Zucker rats was affected by age $\left(\mathrm{F}_{(1,24)}=8.172, p=0.009\right)$, independently of obesity $\left(\mathrm{F}_{(1,24)}=0.989, p=0.330\right)($ Figure $2 \mathrm{~A})$. Aging increased the cytosolic lipin-1 content.

Regarding lipin-1 content in nuclear extract of muscle cells, the two-way ANOVA revealed a significant interaction between age and $f a / f a$ genotype $\left(\mathrm{F}_{(1,19)}=7.323, p=0.014\right)$ (Figure 2B). Post hoc analysis revealed significantly increased lipin-1 content in nuclear extract of old lean rats compared with young lean rats $(p=0.007)$ and significantly decreased level of nuclear extract lipin-1 in old obese rats compared to that in old lean rats $(p=0.017)$.

B
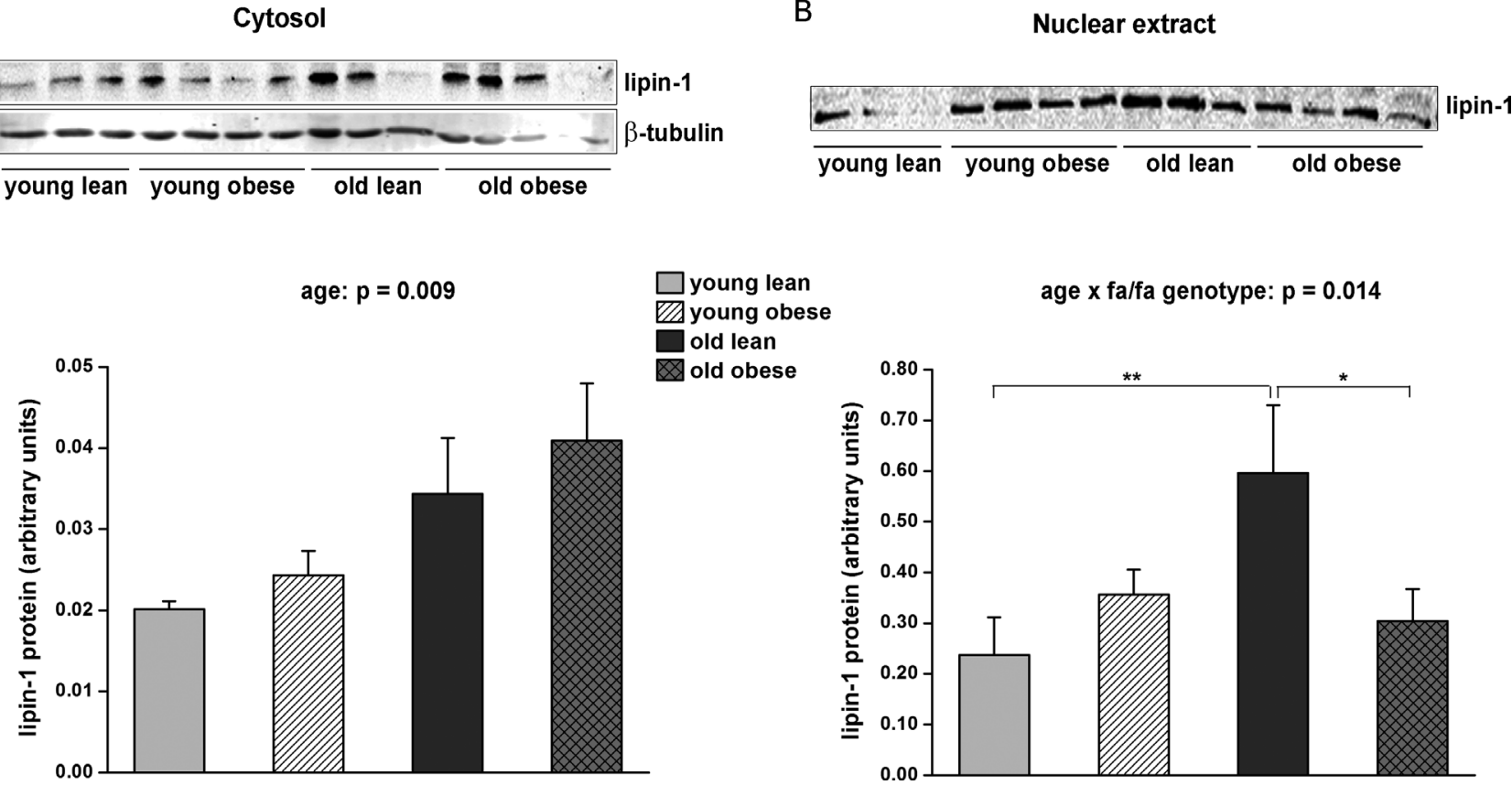

Figure 2. Lipin-1 protein content in cytosol (A) and nuclear extract (B) in quadriceps muscle of 3- (young) and 8-months-old (old) obese Zucker $f a / f a$ rats and their lean controls (lean). Representative Western blots are shown. Results of densitometric quantification of the Western blots after normalization to appropriate loading control are presented as mean \pm SEM. Statistical analysis was calculated by two-way ANOVA, followed by Bonferroni post hoc test. Cytosol: $n=8$ for young obese, $n=8$ for old obese, $n=6$ for young lean and $n=6$ for old lean. Nuclear extract: $n=7$ for young obese, $n=7$ for old obese, $n=5$ for young lean and $n=4$ for old lean. $p<0.05,{ }^{* *} p<0.01$. 
A

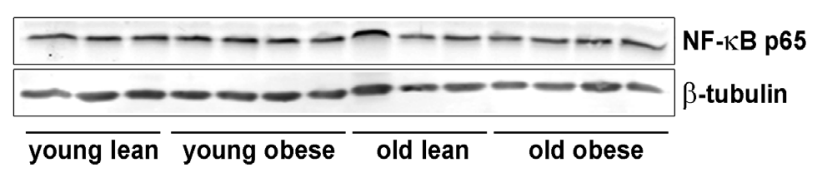

B

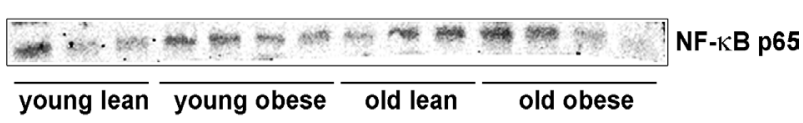

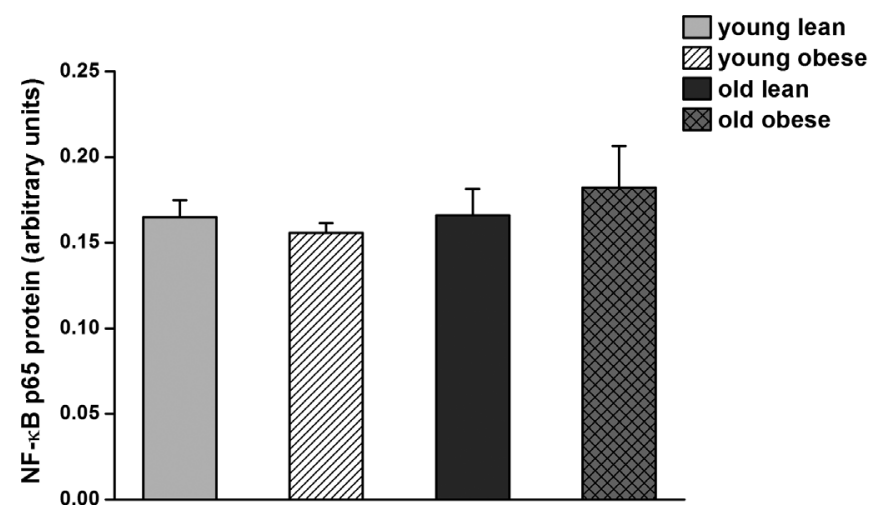

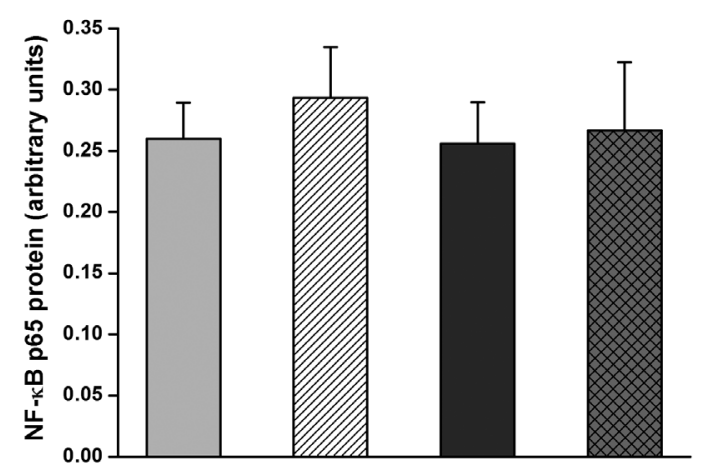

Figure 3. NF- $\kappa \mathrm{B}$ p65 protein content in cytosol (A) and nuclear extract (B) in quadriceps muscle of 3- (young) and 8-months-old (old) obese Zucker fa/fa rats and their lean controls (lean). Representative Western blots are shown. Results of densitometric quantification of the Western blots after normalization to appropriate loading control are presented as mean \pm SEM. Statistical analysis was calculated by two-way ANOVA, followed by Bonferroni post hoc test. Cytosol: $n=8$ for young obese, $n=8$ for old obese, $n=6$ for young lean and $n=6$ for old lean. Nuclear extract: $n=7$ for young obese, $n=7$ for old obese, $n=6$ for young lean and $n=5$ for old lean.

\section{NF- $\kappa B$ p65 content in quadriceps muscle}

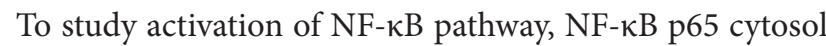
and nuclear distribution was determined. Both NF-kB p65 content in cytosol (Figure 3A) and nucleus (Figure 3B) in quadriceps muscle of Zucker rats were not affected by age $\left(\mathrm{F}_{(1,24)}=0.688, p=0.415 ; \mathrm{F}_{(1,21)}=0.121, p=0.731\right)$ or $f a /$ $f a$ genotype $\left(\mathrm{F}_{(1,24)}=0.0445, p=0.835 ; \mathrm{F}_{(1,21)}=0.258, p=\right.$ $0.617)$, with no age $\times$ genotype interaction $\left(\mathrm{F}_{(1,24)}=0.587\right.$, $\left.p=0.451 ; \mathrm{F}_{(1,21)}=0.0671, p=0.798\right)$.

\section{Discussion}

Obese Zucker rats are homozygous for the mutated $f a$ allele and resulting mutation in the leptin receptor is the molecular base of their characteristic phenotype. Zucker fatty $f a / f a$ rats develop hyperphagia associated with severe obesity. These animals are also model of insulin resistance, because they are dyslipidaemic and hyperinsulinaemic, while glucose levels are normal or only slightly higher than normal (Aleixandre de Artinano and Miguel Castro 2009). As it is already published in the paper by Spolcova et al. (2014), rats from our study developed severe obesity accompanied by metabolic burden such as impaired glucose tolerance only in old age. However, peripheral insulin sensitivity is decreased also at an early age ( 12 weeks) in the $f a / f a$ rats although it is partially compensated at least in terms of glycaemia but not plasma lipid levels (Spolcova et al. 2014).

Aguer and coworkers suggest that FAT/CD36 localization to the membrane is a major contributor to skeletal muscle lipid stores in obesity or type 2 diabetes (Aguer et al. 2010). In this study, the $f a / f a$ rats had increased FAT/CD36 plasma membrane content in quadriceps muscle that most likely leads to increased FA uptake. Study on Zucker diabetic fatty rats in prediabetic state showed that rate of FA uptake and plasma membrane content of FAT/CD36 are upregulated in red skeletal muscle in insulin resistance (Chabowski et al. 2006). Obesity-related increase in plasma membrane localization of FAT/CD36 in young rats is probably due to translocation of transporter from intracellular compartment, since significantly reduced cytosolic content of FAT/CD36 was found in young obese rats compared to age-matched control. This is in accordance with the study from Han et al. (2007) who have noticed relocation of FAT/CD36 from intracellular compartment to plasma membrane in hindlimb muscle of female obese Zucker rats. In old age higher plasma membrane FAT/CD36 content in fa/fa rats was accompanied by higher cytosolic FAT/CD36 content, indicating overall increased FAT/CD36 expression in quadriceps muscle of old obese rats, probably as consequence of increase in protein expression with obesity progression associated with age. Middle-aged mice on a high-fat diet showed significant weight gain and developed insulin resistance compared to 
age-matched controls and it was associated with elevation of FAT/CD36 expression in skeletal muscle of middle-aged mice (Koonen et al. 2010).

Fatty acids that are taken up into skeletal muscle are primarily oxidized or stored as TG. Increase in FA transport and plasmalemmal FAT/CD36 in skeletal muscle of female obese Zucker rats were accompanied by greater rate of FA oxidation (Holloway et al. 2009). However, despite the increased oxidation, intramuscular TG accumulated, strongly suggesting that increased delivery of FA into muscle can exceed capacity of $\beta$-oxidation, which results in the lipid accumulation (Holloway et al. 2009).

Lipin-1 catalyzes the third step in the Kennedy TG synthesis pathway: the dephosphorylation of phosphatidic acid to form DAG (Kok et al. 2012). Significantly increased lipin-1 content in cytosol in quadriceps muscle was observed in old-age rats from our study. Lipin-1 can translocate to endoplasmic reticulum membrane in response to elevated cellular FA (Reue and Brindley 2008). Also, old lean rats had increased lipin-1 protein content in nuclear extract. Study on tissue-specific lipin transgenic mouse strains showed that enhanced lipin expression in skeletal muscle promotes obesity and obesity-associated insulin resistance (Phan and Reue 2005). Wang et al. (2011) showed that longissimus dorsi muscle of Rongchang obese pigs has a higher level of mRNA for lipin-1 than PIC lean pigs. Lipin-1 stimulates expression of genes involved in FA oxidation via direct physical interactions with peroxisome proliferator-activated receptor alpha $(P P A R \alpha)$ and peroxisome proliferator-activated receptor gama coactivator 1 alpha (PGC-1 $\alpha$ ) in nucleus of liver cells (Finck et al. 2006). So, increased cytosolic and nuclear lipin-1 content in quadriceps muscle of old lean rats may indicate increased FA usage in these animals. Koonen and coworkers suggested that there was shifting in substrate selection from carbohydrates toward FA in middle-aged mice, and they detected increased level of TG in gastrocnemius muscle of old mice (Koonen et al. 2010). Decreased nuclear lipin-1 content in quadriceps muscle of old $f a / f a$ rats suggests attenuated involvement of lipin- 1 in regulation of $\beta$-oxidation gene expression in these animals.

Barma et al. (2009) showed that incubation of L6 skeletal muscle cells with palmitate induced NF- $\mathrm{KB}$ activation and NF- $\mathrm{kB}$ p65 expression, and this was associated with insulin resistance. There were no differences in NF- $\kappa B$ p65 cytosolic and nuclear content between groups in our study, implying absence of age- and obesity-related activation of pro-inflammatory NF- $\mathrm{KB}$ signaling in quadriceps muscle of Zucker rats. Also, high-fat feeding in Wistar rats induced weight gain, but did not modify muscle inflammation, as nuclear NF- $\mathrm{kB}$ p65 and tissue TNFa were not changed in gastrocnemius muscle (Barazzoni et al. 2011). However, other pro-inflammatory pathways, such as p38 MAPK signaling, could be involved in the activation of inflammatory processes in the quadriceps muscle of Zucker rats. Namely, activation of $\mathrm{p} 38 \mathrm{MAPK}$ is found in skeletal muscle cells after exposure to palmitate (Maurya et al. 2014; Jaiswal et al. 2015). Also, increased p38 MAPK activity is probably responsible for chronic inflammation in skeletal muscle during aging process (Papaconstantinou et al. 2015).

Obtained results show that with progression of obesity there is failure in lipin-1 export to nucleus implying possible channeling of large influx of FAT/CD36-mediated FA transport to lipid intermediates accumulation in quadriceps muscle of old $f a / f a$ rats. In addition, unchanged NF- $\mathrm{kB}$ p65 nuclear distribution indicates absence of NF-kB-dependent inflammatory responses in muscle of extremely obese rats.

Acknowledgement. This study was funded by grants VEGA 2/0174/17, APVV-15-0229, APVV-15-0565 and by the Project Grant No. 41009 from the Ministry of Education, Science and Technological Development, Republic of Serbia. Snjezana Romic was recipient of SAIA National Scholarship Programme of the Slovak Republic.

Conflict of interest. The authors declare that they have no conflict of interest.

\section{References}

Aguer C., Mercier J., Man C. Y., Metz L., Bordenave S., Lambert K., Jean E., Lantier L., Bounoua L., Brun J. F., et al. (2010): Intramyocellular lipid accumulation is associated with permanent relocation ex vivo and in vitro of fatty acid translocase (FAT)/ CD36 in obese patients. Diabetologia 53, 1151-1163 https://doi.org/10.1007/s00125-010-1708-X

Aleixandre de Artinano A., Miguel Castro M. (2009): Experimental rat models to study the metabolic syndrome. Br. J. Nutr. 102, $1246-1253$ https://doi.org/10.1017/S0007114509990729

Baker R. G., Hayden M. S., Ghosh S. (2011): NF-kappaB, inflammation, and metabolic disease. Cell Metab. 13, 11-22 https://doi.org/10.1016/j.cmet.2010.12.008

Barazzoni R., Zanetti M., Semolic A., Cattin M. R., Pirulli A., Cattin L., Guarnieri G. (2011): High-fat diet with acyl-ghrelin treatment leads to weight gain with low inflammation, high oxidative capacity and normal triglycerides in rat muscle. PLoS One 6, e26224

https://doi.org/10.1371/journal.pone.0026224

Barma P., Bhattacharya S., Bhattacharya A., Kundu R., Dasgupta S., Biswas A., Roy S. S. (2009): Lipid induced overexpression of NF-kappaB in skeletal muscle cells is linked to insulin resistance. Biochim. Biophys. Acta 1792, 190-200 https://doi.org/10.1016/j.bbadis.2008.11.014

Bonen A., Benton C. R., Campbell S. E., Chabowski A., Clarke D. C., Han X. X., Glatz J. F., Luiken J. J. (2003): Plasmalemmal fatty acid transport is regulated in heart and skeletal muscle by contraction, insulin and leptin, and in obesity and diabetes. Acta Physiol. Scand. 178, 347-356 https://doi.org/10.1046/j.1365-201x.2003.01157.x 
Bonen A., Campbell S. E., Benton C. R., Chabowski A., Coort S. L., Han X. X., Koonen D. P., Glatz J. F., Luiken J. J. (2004a): Regulation of fatty acid transport by fatty acid translocase/ CD36. Proc. Nutr. Soc. 63, 245-249 https://doi.org/10.1079/PNS2004331

Bonen A., Parolin M. L., Steinberg G. R., Calles-Escandon J., Tandon N. N., Glatz J. F., Luiken J. J., Heigenhauser G. J., Dyck D. J. (2004b): Triacylglycerol accumulation in human obesity and type 2 diabetes is associated with increased rates of skeletal muscle fatty acid transport and increased sarcolemmal FAT/ CD36. FASEB J. 18, 1144-1146 https://doi.org/10.1096/fj.03-1065fje

Bonen A., Chabowski A., Luiken J. J., Glatz J. F. (2007): Is membrane transport of FFA mediated by lipid, protein, or both? Mechanisms and regulation of protein-mediated cellular fatty acid uptake: molecular, biochemical, and physiological evidence. Physiol. (Bethesda) 22, 15-29

Brown A. E., Palsgaard J., Borup R., Avery P., Gunn D. A., De Meyts P., Yeaman S. J., Walker M. (2015): p38 MAPK activation upregulates proinflammatory pathways in skeletal muscle cells from insulin-resistant type 2 diabetic patients. Am. J. Physiol. Endocrinol. Metab. 308, E63-70 https://doi.org/10.1152/ajpendo.00115.2014

Cahova M., Vavrinkova H., Kazdova L. (2007): Glucose-fatty acid interaction in skeletal muscle and adipose tissue in insulin resistance. Physiol. Res. 56, 1-15

Chabowski A., Chatham J. C., Tandon N. N., Calles-Escandon J., Glatz J. F., Luiken J. J., Bonen A. (2006): Fatty acid transport and FAT/CD36 are increased in red but not in white skeletal muscle of ZDF rats. Am. J. Physiol. Endocrinol. Metab. 291, E675-682 https://doi.org/10.1152/ajpendo.00096.2006

Donkor J., Sariahmetoglu M., Dewald J., Brindley D. N., Reue K. (2007): Three mammalian lipins act as phosphatidate phosphatases with distinct tissue expression patterns. J. Biol. Chem. 282, 3450-3457 https://doi.org/10.1074/jbc.M610745200

Finck B. N., Gropler M. C., Chen Z., Leone T. C., Croce M. A., Harris T. E., Lawrence J. C., Jr., Kelly D. P. (2006): Lipin 1 is an inducible amplifier of the hepatic PGC-1alpha/PPARalpha regulatory pathway. Cell Metab. 4, 199-210 https://doi.org/10.1016/j.cmet.2006.08.005

Han X. X., Chabowski A., Tandon N. N., Calles-Escandon J., Glatz J. F., Luiken J. J., Bonen A. (2007): Metabolic challenges reveal impaired fatty acid metabolism and translocation of FAT/CD36 but not FABPpm in obese Zucker rat muscle. Am. J. Physiol. Endocrinol. Metab. 293, E566-575 https://doi.org/10.1152/ajpendo.00106.2007

Helenius M., Hanninen M., Lehtinen S. K., Salminen A. (1996): Aging-induced up-regulation of nuclear binding activities of oxidative stress responsive NF-kB transcription factor in mouse cardiac muscle. J. Mol. Cell. Cardiol. 28, 487-498 https://doi.org/10.1006/jmcc.1996.0045

Holloway G. P., Benton C. R., Mullen K. L., Yoshida Y., Snook L. A., Han X. X., Glatz J. F., Luiken J. J., Lally J., Dyck D. J., Bonen A. (2009): In obese rat muscle transport of palmitate is increased and is channeled to triacylglycerol storage despite an increase in mitochondrial palmitate oxidation. Am. J. Physiol. Endocrinol. Metab. 296, E738-747 https://doi.org/10.1152/ajpendo.90896.2008

Huang B., Yang X. D., Lamb A., Chen L. F. (2010): Posttranslational modifications of NF-kappaB: another layer of regulation for NF-kappaB signaling pathway. Cell. Signal. 22, 1282-1290 https://doi.org/10.1016/j.cellsig.2010.03.017

Itani S. I., Ruderman N. B., Schmieder F., Boden G. (2002): Lipidinduced insulin resistance in human muscle is associated with changes in diacylglycerol, protein kinase $\mathrm{C}$, and IkappaB-alpha. Diabetes 51, 2005-2011 https://doi.org/10.2337/diabetes.51.7.2005

Jaiswal N., Gunaganti N., Maurya C. K., Narender T., Tamrakar A. K. (2015): Free fatty acid induced impairment of insulin signaling is prevented by the diastereomeric mixture of calophyllic acid and isocalophyllic acid in skeletal muscle cells. Eur. J. Pharmacol. 746, 70-77 https://doi.org/10.1016/j.ejphar.2014.10.049

Jarett L. (1974): Subcellular fractionation of adipocytes. In: Methods in Enzymology. (Eds. S. Fleischer and L. Packer), Vol. XXXI, Biomembranes, Part A, pp. 60-71, Academic Press, Massachusetts https://doi.org/10.1016/0076-6879(74)31007-5

Kelley D. E., Mandarino L. J. (2000): Fuel selection in human skeletal muscle in insulin resistance: a reexamination. Diabetes 49, 677-683 https://doi.org/10.2337/diabetes.49.5.677

Kok B. P., Venkatraman G., Capatos D., Brindley D. N. (2012): Unlike two peas in a pod: lipid phosphate phosphatases and phosphatidate phosphatases. Chem. Rev. 112, 5121-5146 https://doi.org/10.1021/cr200433m

Koonen D. P., Glatz J. F., Bonen A., Luiken J. J. (2005): Long-chain fatty acid uptake and FAT/CD36 translocation in heart and skeletal muscle. Biochim. Biophys. Acta 1736, 163-180 https://doi.org/10.1016/j.bbalip.2005.08.018

Koonen D. P., Sung M. M., Kao C. K., Dolinsky V. W., Koves T. R., Ilkayeva O., Jacobs R. L., Vance D. E., Light P. E., Muoio D. M., Febbraio M., Dyck J. R. (2010): Alterations in skeletal muscle fatty acid handling predisposes middle-aged mice to diet-induced insulin resistance. Diabetes 59, 1366-1375 https://doi.org/10.2337/db09-1142

Kramer H. F., Goodyear L. J. (2007): Exercise, MAPK, and NF-kappaB signaling in skeletal muscle. J. Appl. Physiol. 103, 388-395 https://doi.org/10.1152/japplphysiol.00085.2007

Li M., Paran C., Wolins N. E., Horowitz J. F. (2011): High muscle lipid content in obesity is not due to enhanced activation of key triglyceride esterification enzymes or the suppression of lipolytic proteins. Am. J. Physiol. Endocrinol. Metab. 300, E699-707 https://doi.org/10.1152/ajpendo.00316.2010

Luiken J. J., Arumugam Y., Dyck D. J., Bell R. C., Pelsers M. M., Turcotte L. P., Tandon N. N., Glatz J. F., Bonen A. (2001): Increased rates of fatty acid uptake and plasmalemmal fatty acid transporters in obese Zucker rats. J. Biol. Chem. 276, 40567-40573 https://doi.org/10.1074/jbc.M100052200

Machann J., Haring H., Schick F., Stumvoll M. (2004): Intramyocellular lipids and insulin resistance. Diabetes Obes. Metab. 6, 239-248 https://doi.org/10.1111/j.1462-8902.2004.00339.x

Maurya C. K., Singh R., Jaiswal N., Venkateswarlu K., Narender T., Tamrakar A. K. (2014): 4-Hydroxyisoleucine ameliorates fatty 
acid-induced insulin resistance and inflammatory response in skeletal muscle cells. Mol. Cell. Endocrinol. 395, 51-60 https://doi.org/10.1016/j.mce.2014.07.018

Papaconstantinou J., Wang C. Z., Zhang M., Yang S., Deford J., Bulavin D. V., Ansari N. H. (2015): Attenuation of p38alpha MAPK stress response signaling delays the in vivo aging of skeletal muscle myofibers and progenitor cells. Aging 7, 718-733 https://doi.org/10.18632/aging.100802

Phan J., Reue K. (2005): Lipin, a lipodystrophy and obesity gene. Cell Metab. 1, 73-83 https://doi.org/10.1016/j.cmet.2004.12.002

Reue K., Brindley D. N. (2008): Thematic review series: Glycerolipids. Multiple roles for lipins/phosphatidate phosphatase enzymes in lipid metabolism. J. Lipid Res. 49, 2493-2503 https://doi.org/10.1194/jlr.R800019-JLR200

Rivas D. A., Morris E. P., Haran P. H., Pasha E. P., Morais Mda S., Dolnikowski G. G., Phillips E. M., Fielding R. A. (2012): Increased ceramide content and NFkappaB signaling may contribute to the attenuation of anabolic signaling after resistance exercise in aged males. J. Appl. Physiol. 113, $1727-1736$

https://doi.org/10.1152/japplphysiol.00412.2012

Siniossoglou S. (2013): Phospholipid metabolism and nuclear function: roles of the lipin family of phosphatidic acid phosphatases. Biochim. Biophys. Acta 1831, 575-581 https://doi.org/10.1016/j.bbalip.2012.09.014

Sishi B., Loos B., Ellis B., Smith W., du Toit E. F., Engelbrecht A. M. (2011): Diet-induced obesity alters signalling pathways and induces atrophy and apoptosis in skeletal muscle in a prediabetic rat model. Exp. Physiol. 96, 179-193 https://doi.org/10.1113/expphysiol.2010.054189

Spolcova A., Mikulaskova B., Krskova K., Gajdosechova L., Zorad S., Olszanecki R., Suski M., Bujak-Gizycka B., Zelezna B.,
Maletinska L. (2014): Deficient hippocampal insulin signaling and augmented Tau phosphorylation is related to obesity- and age-induced peripheral insulin resistance: a study in Zucker rats. BMC Neurosci. 15, 111

https://doi.org/10.1186/1471-2202-15-111

Timmers S., Schrauwen P., de Vogel J. (2008): Muscular diacylglycerol metabolism and insulin resistance. Physiol. Behav. 94, 242-251 https://doi.org/10.1016/j.physbeh.2007.12.002

Tsatsoulis A., Mantzaris M. D., Bellou S., Andrikoula M. (2013): Insulin resistance: an adaptive mechanism becomes maladaptive in the current environment - an evolutionary perspective. Metabolism 62, 622-633 https://doi.org/10.1016/j.metabol.2012.11.004

Tucker M. Z., Turcotte L. P. (2003): Aging is associated with elevated muscle triglyceride content and increased insulin-stimulated fatty acid uptake. Am. J. Physiol. Endocrinol. Metab. 285, E827-835 https://doi.org/10.1152/ajpendo.00222.2002

Wang Q., Ji C., Huang J., Yang F., Zhang H., Liu L., Yin J. (2011): The mRNA of lipin 1 and its isoforms are differently expressed in the longissimus dorsi muscle of obese and lean pigs. Mol. Biol. Rep. 38, 319-325 https://doi.org/10.1007/s11033-010-0110-6

Welinder C., Ekblad L. (2011): Coomassie staining as loading control in Western blot analysis. J. Proteome Res. 10, 1416-1419 https://doi.org/10.1021/pr1011476

Ye J. (2013): Mechanisms of insulin resistance in obesity. Front. Med. 7, 14-24 https://doi.org/10.1007/s11684-013-0262-6

Received: September 9, 2016

Final version acepted: March 1, 2017

First published online: June 27, 2017 